\title{
Core-shell nanofibers as drug delivery systems
}

\author{
ŠPELA ZUPANČIČ \\ Faculty of Pharmacy, University of \\ Ljubljana, 1000 Ljubljana, Slovenia
}

Accepted November 4, 2018

Published online November 14, 2018

\begin{abstract}
Core-shell nanofibers have grown in popularity over the last decade owing to their special features and their many applications in biomedicine. They can be produced by electrospinning of immiscible polymer blends or emulsions through a single nozzle or by electrospinning using a coaxial nozzle. Several of the electrospinning parameters allow great versatility for the compositions and diameters of core-shell nanofibers to be produced. Morphology of core-shell nanofibers can be investigated using transmission electron microscopy and, in some cases, scanning electron microscopy. Several studies have shown that core-shell nanofibers have some advantages over monolithic nanofibers, such as better drug, protein, gene or probiotic incorporation into the nanofibers, greater control over drug release, and maintenance of protein structure and activity during electrospinning. We herein review the production and characterization of core-shell nanofibers, the critical parameters that affect their development, and their advantages as delivery systems.

Keywords: coaxial electrospinning, emulsion electrospinning, core-shell nanofibers, nanotechnology, nanodelivery system, drug release
\end{abstract}

\section{INTRODUCTION}

Nanofibers and microfibers can have diameters of a few nanometers to several micrometers. They are composed of natural and/or synthetic polymers, and are most frequently produced using the electrospinning technique (1). Over the last few decades, electrospinning has grown in popularity and is now used for the production of different monolithic or blended nanofibers for several applications (2). In 2003, coaxial electrospinning was discovered to be a promising method for the preparation of a novel class of nanofibers with core-shell or core-sheath structures using a coaxial nozzle (3). Three years later, emulsion electrospinning using a single nozzle was shown to produce similarly structured nanofibers (4).

Interest in nanofibers rapidly increased in the last decade, with 56 articles published in 2004, while since 2014 more than 1000 articles have been published each year (Fig. 1).

*Correspondence; e-mail: spela.zupancic@ffa.uni-lj.si 


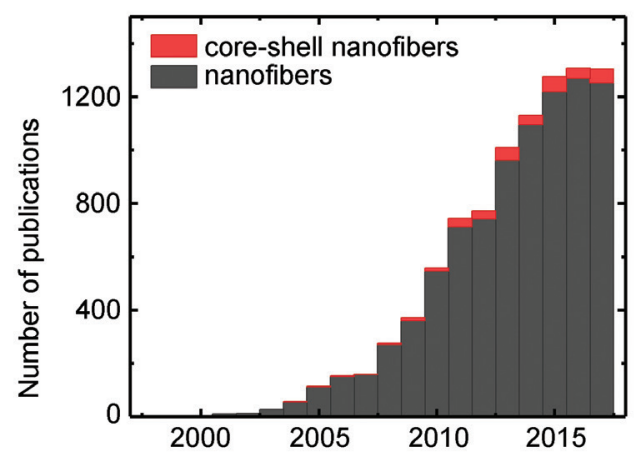

Fig. 1. The number of publications on nanofibers and core-shell nanofibers published between 1996 and 2017 (source: PubMed).

Interest in core-shell nanofibers has also increased, and they have represented 1 to $5 \%$ of all nanofiber publications over these years.

Polymeric nanofibers have several remarkable features, which include nanoscale diameters, unlimited lengths (theoretically), high surface-to-volume ratios, and porous structures, both individually and as mats. These characteristics have provided them with improved mechanical performance and flexibility compared to any other forms of the same material $(2,5,6)$. Therefore, in the last 15 years, electrospun fibers have emerged as promising materials in many fields, including filtration (7), packaging (8), electronics (9), and biomedicine. In biomedicine in particular, as nanofibers have the striking feature that they resemble an extracellular matrix, they have grown in popularity as drug delivery systems and as powerful materials for tissue engineering $(10,11)$.

Although monolithic and blended nanofibers have promising characteristics, there are some disadvantages that provide considerable challenges, such as their incorporation of hydrophilic drugs, proteins, and cells, with their high drug loading and preserved drug or protein activity, and their prolonged release without burst effects (12). Therefore, several studies have developed core-shell nanofibers to solve these problems. This review focuses on the methods for the production of core-shell nanofibers as a single step, parameters that affect these processes, characterization techniques, and presentation of core-shell nanofibers as a drug delivery system.

\section{INTRODUCTION TO ELECTROSPINNING}

Electrospinning is the process that produces nanofibers and microfibers from viscoelastic polymer solutions or melts. An electrospinning set-up consists of a pump, a single, coaxial, or triaxial nozzle, a high-voltage source applied to the nozzle, and a grounded or oppositely charged collector (Fig. 2). A polymer dispersion (i.e., solution, miscible polymer blend, immiscible polymer blend, emulsion) is pumped through the nozzle, on the tip of which a drop appears, which is held by surface-tension forces $(4,13-15)$. When high voltage is applied to the nozzle, charge is induced within the polymer dispersion. When electrical forces overcome those of the droplet surface tension in the charged polymer solution, a 

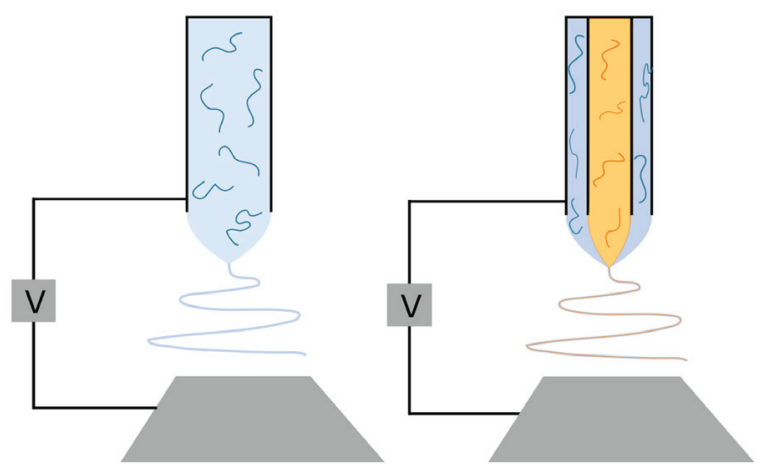

Fig. 2. Schematic representation of electrospinning through a single and a coaxial nozzle.

Taylor cone is formed and the jet is pulled by the electric field toward the grounded collector. The jet undergoes stretching and whipping, and it solidifies due to solvent evaporation before it is deposited as a nanofiber mat on the grounded collector (13). The electrospinning process is influenced by the dispersion used (e.g., polymer type, concentration, viscosity, conductivity, surface tension), the processing factors (e.g., electric field strength, flow rate, collector set-up), and the ambient parameters (e.g., temperature, humidity), which have been previously described in detail $(1,2,13,16,17)$.

\section{Electrospinning using a single nozzle for the production of core-shell nanofibers}

A single nozzle is commonly used for the electrospinning of nanofibers that are formed from one polymer (monolithic) or more polymers (blended). However, in special cases, electrospinning of polymer blends and emulsions can result in core-shell nanofibers (Fig. 3).

Electrospinning of immiscible polymer blends. - Polymer mixtures can be classified as miscible or immiscible polymer blends. Miscible polymer blends can form solutions without any phase separation between the ingredient polymers (Fig. 3b). In contrast, immiscible polymer blends in the same solvent separate into two or more phases (Fig. 3c) due to their thermodynamic incompatibility $(15,18,19)$. A few examples of immiscible polymer blends that have been electrospun into core-shell nanofibers include poly(methyl methacrylate) (PMMA)/polyacrylonitrile (PAN) in a 1:1 mass ratio dissolved in dimethylformamide (DMF) (15), and PMMA/polycarbonate, polystyrene/PMMA, polybutadiene/polycarbonate, polyaniline/polystyrene and polyaniline/polycarbonate, all of which were separately dissolved in tetrahydrofuran (THF) in a 1:3 mass ratio (20). Electrospinning of poly(vinyl pyrrolidone) and tetraethyl orthosilicate blends in ethanol produces nanotubes in a single step (21).

Detailed explanation of the formation of core-shell fibers from electrospinning of polymer blends was provided by Bazilevsky et al. (16). Briefly, their PMMA/PAN blend in DMF provided 100 to $200 \mu \mathrm{m}$ PMMA/DMF drops. During electrospinning, on the tip of the nozzle, a drop of the inner polymer is covered with the continuous phase of the other 
Dispersion

a) Polymer solution

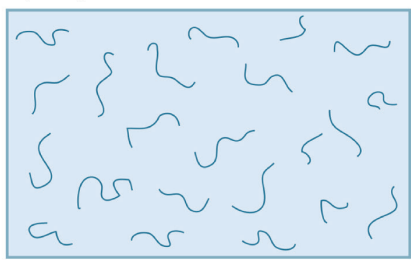

b) Miscible polymer blend

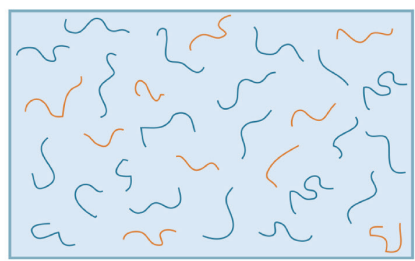

c) Immiscible polymer blend

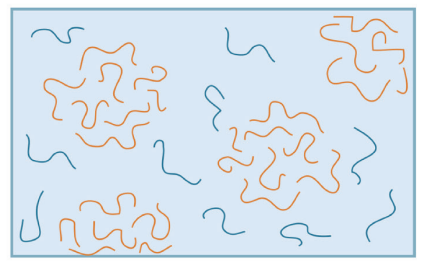

d) Emulsion

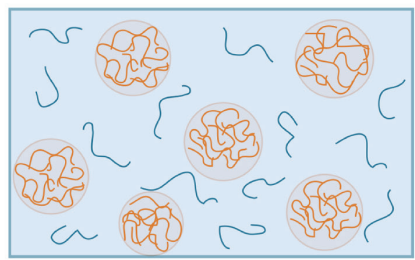

Legend:

Polymer A $ح$

Polymer B
Electrospinning

Nanofibers
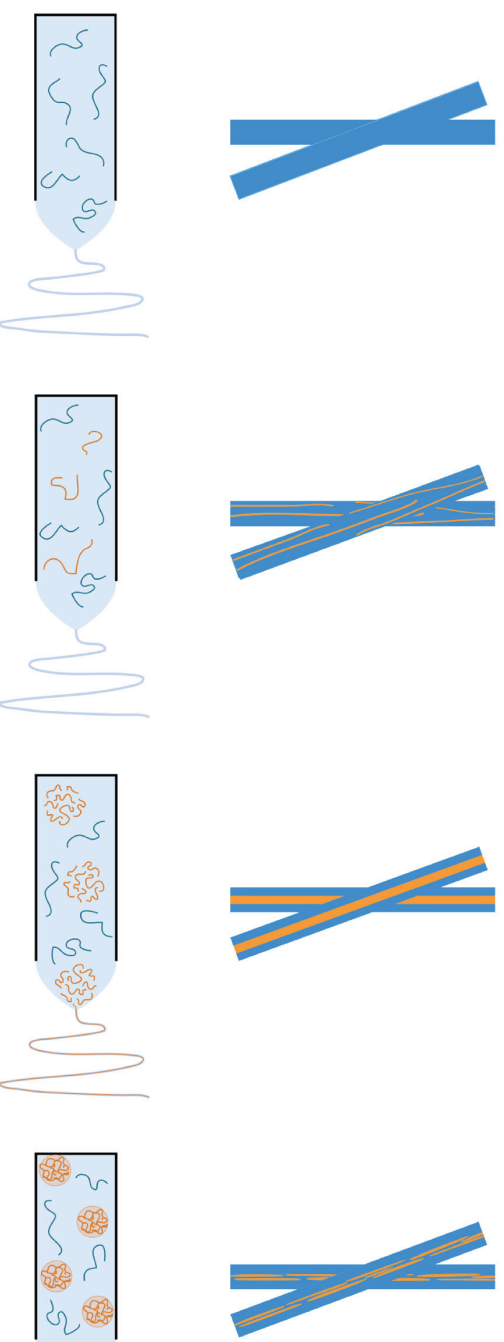

28

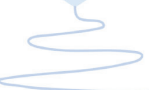

Solvent A

Solvent B

Fig. 3. Schematic representation of polymer dispersions: a) as polymer solution, b) miscible polymer blend, c) immiscible polymer blend, and d) emulsion. These can be electrospun to form: a) monolithic, b) blended, and c, d) core-shell nanofibers. Electrospinning of immiscible polymer blends and emulsions only under optimized conditions results in core-shell nanofibers. 
polymer (Fig. 3c). When the electrical forces are sufficiently strong, a continuous phase entraps and sucks the drop into a core-shell jet, which can result in core-shell fibers. Theoretically, after electrospinning, one drop of inner phase with a diameter of $100 \mu \mathrm{m}$ on the tip of the nozzle can result in a 1-m-long core of core-shell fiber with a diameter of $1 \mu \mathrm{m}$. As there are no indications of long fiber sections without a core, which are quite common for core-shell nanofibers produced by coaxial electrospinning, the process appears to be relatively robust (15). In addition, electrospinning of immiscible polymer blends with smaller drops can lead to multi-core or co-continuous fibers $(14,15,18,20)$.

Although polymer blends are often electrospun, formation of core-shell nanofibers from them has rarely been reported. One reason might be that the nanofiber morphology has seldom been studied using transmission electron microscopy when core-shell nanofibers are not expected. Furthermore, there is a narrow window of parameters under which core-shell nanofibers can be formed. The most critical parameter for the formation of coreshell nanofibers is low molecular weight of the polymer, since during electrospinning, polymers with higher mobility will preferentially organize into a core-shell rather than a co-continuous structure. Thermodynamic properties that favor the formation of core-shell structure include incompatibility between the two polymers and a large difference in their solubility parameters. Here, also, the more viscous phase was reported to form the core (20).

Emulsion electrospinning. - Emulsions are mixtures of two or more immiscible liquids, where one liquid is usually dispersed as drops in the other, which is seen as a continuous phase (Fig. 3d). Electrospinning of emulsions through a single nozzle (i.e., emulsion electrospinning) represents one of the ways to prepare core-shell fibers with successful incorporation of drugs, proteins and microspheres $(4,15,20,22)$. For the two types of emulsions, oil-in-water (23) and water-in-oil $(4,22,24-27)$, the use of water-in-oil emulsions has been more often reported in the literature. Water-in-oil emulsions frequently consist of an aqueous polymer solution with a dissolved hydrophilic drug or protein as the dispersed phase, with the continuous phase of a solution of hydrophobic polymer in an organic solvent, such as chloroform $(4,27,28)$. Surfactants are usually added to increase the physical stability of emulsions $(4,22,24-27)$. Emulsion electrospinning of oil-in-water emulsions tends to consist of aqueous polymer solutions, thus avoiding harmful organic solvents, referred to as 'green electrospinning' (29). In such cases, the dispersed phase is an oil (e.g., mineral or plant oil), which is used for incorporation of hydrophobic drugs into hydrophilic nanofibers $(23,29)$.

In the literature, the formation of core-shell nanofibers prepared using water-in-oil emulsion electrospinning has been explained as follows: during the electrospinning process, the drops stretch into an elliptical shape in the direction of the fiber due to the interfacial shear forces from the outer oil phase. Drops that are too large to resist the electric force break up into smaller drops. Viscosity of the oil phase increases more rapidly than the inner aqueous drops, which directs the drops to be incorporated into the fiber interior, rather than to be at the surface $(4,30)$. If the drops merge, they form the core, and thus emulsion electrospinning results in core-shell nanofibers $(4,25,27,28,31-33)$. Instead of core-shell morphology, separate drops embedded into the fibers $(4,34)$ and discontinuous core (24) have also been reported.

Polymer concentration in an emulsion has a critical role in the formation of nanofibers (35), similar to what has been reported for electrospinning of polymer solutions (17). Elec- 
trospinning of emulsions with low polymer concentrations results in beaded nanofiber morphology, due to low viscoelasticity, and thus sufficient polymer concentration and polymer weight are needed for the formation of smooth nanofibers (35). Continuous phase should also show electrospinnability, but if the dispersed phase is not electrospinnable, core-shell nanofibers can still be formed (27). A dispersed phase of the emulsion with a high polymer concentration results in a thicker core and overall fiber diameter after electrospinning compared to lower polymer concentrations (4).

The volume ratio of the dispersed phase to the continuous phase of the emulsion influences the inner structure and diameter of the fibers that can be formed $(27,35)$. A high water content for the dispersed phase in a water-in-oil emulsion leads to less uniform nanofibers (35) and incomplete movement of the emulsion droplets during electrospinning to the core thus, this results in core material close to the nanofiber surface. In addition, higher water contents in a water-in-oil emulsion results in decreased nanofiber diameter due to higher conductivity of the emulsion (27). In contrast, for an oil-in-water emulsion, the addition of plant oil into an aqueous poly(vinyl alcohol) (PVA) solution increases the emulsion viscosity, and consequently results in thicker fibers (23).

\section{Coaxial electrospinning: electrospinning using a coaxial nozzle for the production of core-shell nanofibers}

Coaxial electrospinning is the process that is now most often used for the production of core-shell nanofibers. In terms of immiscible polymer blended and emulsion electrospinning, coaxial electrospinning differs due to the pumping of two separate solutions through a coaxial nozzle, instead of one solution/emulsion though a single nozzle (Fig. 2) (18). The core and shell solutions can be composed of the same (3) or different $(18,36)$ polymers, and sometimes the core consists of the drug solution only without any polymer added (37). According to some studies, both solutions need to be spinnable, whereas other studies have claimed that coaxial electrospinning is important for core materials that cannot form nanofibers by themselves such as nonpolymeric Newtonian liquids (38). In addition, coaxial electrospinning can result in the formation of nanotubes (39).

For coaxial electrospinning, the core-shell droplet appears at the tip of the coaxial nozzle, which at the applied voltage ejects the core-shell jet. This undergoes similar electrically driven bending instabilities as for the ordinary electrospinning process. Importantly, use of the core-shell nozzle does not guarantee formation of a core-shell jet and later on core-shell nanofibers, since there are also many parameters (e.g., solutions, processing, environmental) involved during coaxial electrospinning. In some cases, the core jet might not enter the shell jet, which will result in a monolithic core and/or shell nanofibers or beads. In particular, two types of capillary instabilities can affect core-shell jets. First, as with standard electrospinning, the whole jet can break up into droplets, due to surface tension and insufficient viscoelastic forces. The other instability is specific to the core-shell jet, where the core solution during coaxial electrospinning can break up into separate droplets inside an intact shell due to the interfacial tension between these two solutions (38).

There are a number of additional parameters that are important in core-shell nanofiber preparation, compared to electrospinning of monolithic nanofibers. These are the miscibility or immiscibility of the core and shell solutions, the flow rate ratio between the two solutions, and the protrusion of the core nozzle outside the shell nozzle (40). 
Core-shell nanofibers can be prepared from the same polymer and the same solvent mixture as the core and shell (3), different polymers dissolved in the same solvents as the core and shell $(3,18,41)$, and different polymers dissolved in different solvents, which can be miscible, partially miscible, or immiscible $(36,42)$. Solvent miscibility between the core and shell solutions is an important parameter to consider, as this can affect the core-shell nanofiber formation and their morphology. Zussman et al. (43) have reported that a wellstabilized coaxial-electrospinning process can be achieved when both solutions are sufficiently viscous, spinnable, and immiscible. Chakraboty et al. (42) indicated that complete immiscibility between the core and shell solutions (e.g., water and chloroform) leads to uneven distribution of the core solution (i.e., water) inside the fiber, which increases the probability of defects. Decreased interfacial tension caused by the addition of a common secondary solvent results in fewer defects, an even distribution of the water inside the fiber, and thinner and uniform core-shell nanofibers $(42,44)$. Using the same solvent system for shell and core solutions decreases the interfacial tension (18), although in such cases a less sharp boundary between the core and shell systems has been suggested (43). On the other hand, theoretically, a sharp boundary between two identical polymers in core-shell nanofibers can be obtained because the characteristic time of diffusion spreading of a polymer in core-shell nanofibers is 10-fold greater compared to the solidification process (3).

The flow rate ratio between the core and shell solutions in coaxial electrospinning is crucial for the formulation of core-shell nanofibers. At core-shell flow rate ratios of $<1: 2$, there is insufficient shell solution to coat the core solution, which results in droplets or particles on the collector. Increased core-shell flow rate ratios (1:2 to 1:3) lead to occasional encapsulation of the core solution in the core-shell nanofibers, accompanied by many defects, such as an incomplete shell. The optimum core-shell flow rate ratios are 1:3 to 1:6, which enable the formation of a stable core-shell Taylor cone and result in formation of core-shell nanofibers. Raising the core-shell flow rate ratio from 1:7 to 1:10 does not appear to affect the ability of the core-shell solutions to be electrospun, but reduces the amount of core in the core-shell nanofibers formed $(18,42)$.

The position of the coaxial needle is also important for successful core-shell nanofiber preparation. It has been shown, both theoretically and experimentally, that the core nozzle needs to be outside its shell counterpart by about half the radius of the shell (40). Coaxial electrospinning can be also typically achieved at an applied voltage similar to that for single electrospinning, although poor miscibility between core and shell solutions can require higher voltage to be applied so as to overcome the interfacial tension between the core and shell (42).

\section{CHARACTERIZATION OF POLYMER SOLUTIONS/EMULSIONS AND CORE-SHELL NANOFIBERS}

\section{Polymer solution and emulsion characterization}

Optimum solution properties are among the most important aspects for successful nanofiber formation. Solution parameters that are usually measured are shear viscosity, conductivity, and surface tension (Table I) $(1,45,46)$. Rheometers with a cone-plate measuring system are used to perform the rotational and oscillatory tests to define the shear viscosity and elastic $\left(G^{\prime}\right)$ and plastic $\left(G^{\prime \prime}\right)$ moduli of solutions $(17,39,47)$. Interfacial shear 
Table I. Methods that can be used for characterization of core-shell nanofibers

\begin{tabular}{|c|c|c|}
\hline Character & Method & Reference \\
\hline \multirow[t]{7}{*}{ Solution/emulsion characterization } & Bulk viscosity & $17,39,47,54$ \\
\hline & Interfacial shear rheology & 46,48 \\
\hline & Elongational rheology & 49 \\
\hline & Conductivity & 43,59 \\
\hline & Surface tension & 60 \\
\hline & Interfacial tension & 50 \\
\hline & Optical and fluorescence microscopy & 15,18 \\
\hline \multirow{8}{*}{$\begin{array}{l}\text { Nanofiber morphology and drug } \\
\text { distribution }\end{array}$} & Scanning electron microscopy & $18,24,53,54$ \\
\hline & $\begin{array}{l}\text { Field-emission scanning electron } \\
\text { microscopy }\end{array}$ & 56 \\
\hline & $\begin{array}{l}\text { Environmental scanning electron } \\
\text { microscopy }\end{array}$ & 54 \\
\hline & Transmission electron microscopy & 24,56 \\
\hline & Optical light or fluorescence microscopy & 15,18 \\
\hline & Atomic force microscopy & 61 \\
\hline & Energy dispersive $\mathrm{X}$-ray spectroscopy & 56 \\
\hline & Electron spectroscopy for chemical analysis & 56 \\
\hline \multirow{3}{*}{$\begin{array}{l}\text { Solid state analysis and interactions } \\
\text { between nanofiber components }\end{array}$} & X-ray diffraction & 56 \\
\hline & Differential scanning calorimetry & 18,54 \\
\hline & $\begin{array}{l}\text { Attenuated total reflectance Fourier } \\
\text { transform infrared spectroscopy }\end{array}$ & 18,54 \\
\hline \multirow[t]{4}{*}{ Porosity } & Capillary flow porosimetry & 56 \\
\hline & Mercury porosimetry & 62 \\
\hline & Scanning electron microscopy images & 63 \\
\hline & Micro-computed tomography & 64 \\
\hline Hydrophobicity & Water contact angle & $24,53,54,65,66$ \\
\hline Permeability & Permeation test & 56 \\
\hline \multirow[t]{2}{*}{ Mechanical properties } & Atomic force microscopy & 65,67 \\
\hline & Tensile testing & $24,56,66$ \\
\hline \multirow[t]{2}{*}{ Release studies } & Pharmacopean apparatus & 68 \\
\hline & Modified release tests & $69-72$ \\
\hline
\end{tabular}

rheology enables even better correlation between the rheological characteristics of the interface and the nanofiber morphology, as this gets closer to actual electrospinning conditions $(46,48)$. In addition, elongational rheology is a relatively new method for determina- 

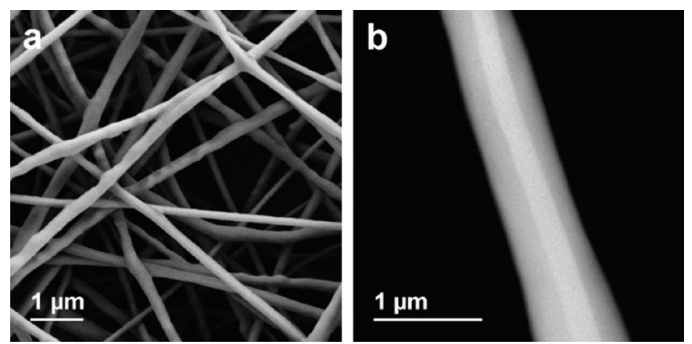

Fig. 4. Representative images of core-shell nanofibers obtained by: a) scanning electron microscopy and b) transmission electron microscopy.
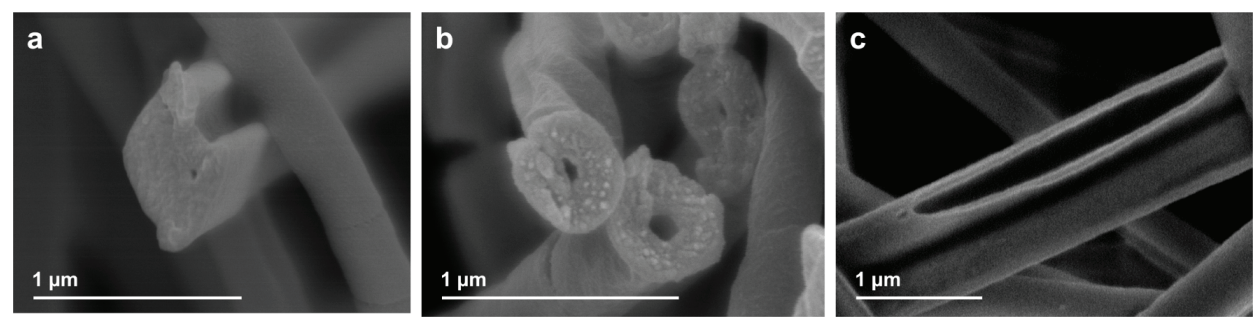

Fig. 5. Scanning electron microscopy images of core-shell nanofibers, where ciprofloxacin was incorporated into a poly(vinyl alcohol) core, with the shell formed with poly(methyl methacrylate) to prolong drug release: a) before and b, c) after ciprofloxacin release. The study is presented in detail in (18).

tion of viscoelasticity; it is based on uniaxial elongational flow that results in self-thinning threads. Elongational rheology can be used to predict solution spinnability and to differentiate between the rheological properties of different polymer solutions (49). Also, special attention needs to be paid to the interfacial tension, which can be measured by a contactangle system using the pendent droplet method, since it influences the stability of the core-shell jet of two immiscible solutions (50). Phase separation of two immiscible polymers and the size of drops in the emulsion can be determined using optical and fluorescence microscopy $(15,18)$.

\section{Nanofiber morphology}

Nanofiber morphology affects the nanofiber performance, including their drug-release kinetics (51) and the responses of cells to the scaffold (52). Physical characterization of nanofibers in terms of their structure and morphology is usually carried out using electron microscopy. Geometric properties of nanofibers, including their diameter, diameter distribution, orientation, and morphology (e.g., cross-section shape, surface roughness) are most frequently examined using scanning electron microscopy and its variations (Fig. 4a) (18, 24, 53, 54). Cross-sections are used to check the core-shell structure, particularly before and after a particular treatment that can remove the core (e.g., heating, immersion in water) (Fig. 5) $(18,55,56)$. Transmission electron microscopy is an alternative for measuring the diameters of extremely small nanofibers $(<300 \mathrm{~nm})$ due to the better resolu- 
tion obtained. Indeed, transmission electron microscopy is commonly used to determine the internal structure of core-shell nanofibers, especially to demonstrate the core-shell morphology (Fig. 4b) $(32,57,58)$. However, studies often provide only one image of their core-shell nanofibers, which might not be a true representation of all of the nanofibers in a nanofiber mat. With microfibers, the core-shell structure can be also seen using light or fluorescence optical microscopy (15). Fluorescence microscopy, energy dispersive X-ray spectroscopy, and electron spectroscopy for chemical analysis can be also used for determination of the distribution of a drug, dye, or metal nanoparticles incorporated into coreshell nanofibers (56). Atomic force microscopy can be used to visualize the three-dimensional structure of the nanofiber mat morphology, single nanofiber and for nanofiber swelling rate in an aqueous medium $(1,6)$, although the process of obtaining an accurate measurement is relatively difficult due to tip convolution (2).

Understanding of the solid states of the drug and polymer incorporated into nanofibers can contribute to easier explanation of the drug-release kinetics and their mechanism. For the polymer, drug, and other excipients, crystallinity within the nanofibers can be examined using $X$-ray diffraction and differential scanning calorimetry, while attenuated total reflectance Fourier transform infrared spectroscopy can be used to determine interactions between the drug and excipients $(2,32,58)$.

\section{Porosity of nanofiber mats}

Nanofiber porosity is another geometric parameter important to tissue engineering. Pore size measurements can be made using scanning electron microscopy images (63), capillary flow porometry (26), and micro-computed tomography (64, 73), and also using mercury porosimetry (62). Electrospun nanofiber mats are usually highly porous structures with $>90 \%$ porosity, total pore volume $\sim 10 \mathrm{~mL} \mathrm{~g}^{-1}$, total pore area of $23 \mathrm{~m}^{2} \mathrm{~g}^{-1}$, and usually nonordered pores with diameters from $2 \mu \mathrm{m}$ to $465 \mu \mathrm{m}$ (2). Limitations of mercury porosimetry are the possible collapse and compression of the scaffold during measurements, so this is not advised for electrospun scaffolds comprising fibers with diameters $<3 \mu \mathrm{m}(62$, 73). Other methods for measuring nanofiber mat porosity include calculations using the density of the material and the volume of the nanofiber mat (10). Alternatively, porosity can be calculated on the basis of scanning electron microscopy image analysis, where the data can be only used for comparisons between nanofiber mats developed and characterized within a single study. This limitation applies because measurements depend on the contrast and brightness of the images obtained, and the number of layers being analyzed (63). Quynh P. Pham et al. compared the porosity of fiber mats using three techniques: mercury porosimetry, liquid intrusion, and gravimetry (62). They showed no statistical differences between these measures. An excellent review of the advantages and limitations of different measurement techniques for porosity was written by Ho and Hutmacher (73).

\section{Hydrophobicity of nanofiber mats}

Hydrophobicity of nanofiber mats has a key role in the determination of their overall performance; in particular, hydrophobicity can affect drug release (74-76), degradation of the polymer matrix in aqueous media (77), and cell adhesion, proliferation, and penetration into nanofiber mats $(65,78,79)$. Nanofiber mats formed from hydrophobic polymers are usually more hydrophobic compared to polymer films from the same polymers due to 
the air captured in the pores between the nanofibers $(76,80)$. Hydrophobicity is most often determined using the water contact angle (53). In addition, this can detect the surface composition of core-shell nanofibers, especially if a hydrophilic core is incorporated into a hydrophobic shell. With complete core incorporation, the water contact angle does not change, or changes minimally, while the diffusion of the core hydrophilic components to the nanofiber surface reduces the water contact angle $(35,53,66)$.

\section{Permeability of nanofiber mats}

Nanofiber mats are also studied as physical membranes that can be introduced during tendon or periodontal surgery to create a protective shield between the tendon/periodontium and its surrounding tissues $(56,81)$. An efficient membrane should prevent fibroblast penetration but still allow nutrient transport through the micron-sized pores. To measure the permeability of nanofiber mats, a permeation test can be performed using a side-byside permeation chamber and bovine serum albumin as the permeation molecule (56).

\section{Mechanical properties}

Mechanical properties of a nanofiber matrix are crucial for biomedical applications such as scaffolds, because a mat must withstand the forces exerted by growing tissue and the physiological activity related to biomechanics, e.g., pulsed blood flow (2). In addition, the mechanical properties of nanofiber mats that resemble the extracellular matrix in vivo provide better material performance for tissue regeneration (65). Mechanical characterization involves a variety of approaches, which include nano-indentation, bending tests, resonance frequency measurements, and microscale tension tests (2). Atomic force microscopy can be used for the determination of Young's modulus of a single nanofiber $(1,6,65)$.

\section{Drug release studies}

Drug release is one of the most important tests for evaluation of novel nanodelivery systems, especially if it predicts the in vivo performance at the application site (82). As nanofiber systems do not have their own monography in the European Pharmacopoeia, the standard dissolution method for solid dose forms using a dissolution apparatus such as 'Apparatus 1' can be used to perform release studies (83). Many drug-loaded nanofiber systems have been investigated under 'sink' conditions using smaller volumes $(<500 \mathrm{~mL}$ as the minimum suggested in the European Pharmacopeia) and various stirring or shaking devices (69-72). These modified tests can be chosen to resemble more closely the in vivo conditions or for practical reasons such as needing lower nanofiber mass for the release test, or problems with the availability of Apparatus I if release studies are longer than a few days or weeks.

\section{CORE-SHELL NANOFIBERS AS DRUG DELIVERY SYSTEMS}

Drug release parameters have been investigated for a number of drugs incorporated into monolithic, blended, or core-shell nanofibers. Polymers used for biomedical applications must be biocompatible, with bioadhesive and biodegradable properties usually desir- 
able (1). Material selection is of critical importance for the production of such nanofibers, because it affects their morphology, biocompatibility, mechanical strength, degradation rate, and release profile, and also their interactions with cells, which can result in a range of tissue responses $(83,84)$. Here, some functional properties of core-shell nanofibers as drug delivery systems are presented.

\section{Immediate release of poorly water-soluble drugs}

In drug discovery, $70 \%$ of new drug candidates have low aqueous solubility, which results in poor oral bioavailability. The need to improve drug bioavailability by enhancing the solubility and dissolution rate is one of the important challenges to solve in pharmaceutical technology (85). Nanofibers represent a promising nanodelivery system for this application, since their characteristics include high surface-to-volume ratio, high porosity of nanofiber mats, nanometer diameters, and possible drug amorphization due to the rapid solidification process (1), which has been already shown for blended poly(ethylene oxide) (PEO)/poloxamer nanofibers loaded with carvedilol (86). In addition, coaxial electrospinning assists in the preparation of solid dispersions of core-shell nanofibers, with simultaneous incorporation of a poorly water-soluble drug and different functional ingredients, which can improve the dissolution and permeation properties of the incorporated drug. Yu et al. (87) showed that using polyvinylpyrrolidone core-shell nanofibers, acyclovir as a model drug can be incorporated into the core, while sodium dodecyl sulfate (a transmembrane enhancer) and sucralose (a sweetener) can be incorporated into the shell. These core-shell nanofibers can rapidly release the acyclovir $(<1 \mathrm{~min})$, with a $>6$-fold increased permeation rate compared to acyclovir powder, as shown by in vitro dissolution and permeation studies. A slightly different concept was shown in a study of Li et al. (88), who prepared core-shell nanofibers with tamoxifen citrate or quercetin, with sodium dodecyl sulfate and poly(vinyl pyrrolidone) $\mathrm{K} 90$ as the shell and poly( $\varepsilon$-caprolactone) (PCL) as the core. Shell thickness was $<100 \mathrm{~nm}$ and thus presented an extremely thin diffusion boundary layer, which increased the dissolution rate of incorporated drugs. Nanofibers that promote rapid release, especially for poorly water-soluble drugs, have the potential to be used as solid dispersions and oral rapid disintegration drug delivery systems (89).

\section{Delayed drug release}

The most common examples of delayed drug release are the delivery systems that can ensure drug release in the upper part of the small intestine after the formulation has passed the stomach. Such delivery systems are also known as gastro-resistant and they usually contain polymers that are insoluble at low $\mathrm{pH}$ and that can trigger drug release at higher $\mathrm{pH}$, due to their increased solubility under these conditions (90).

Co-axial and emulsion electrospinning have been used to prepare gastro-resistant nanofibers, with the aims to protect acid-sensitive drugs/proteins from the low $\mathrm{pH}$ and enzymes in the stomach (91), to provide local treatments of colon diseases (e.g., for delivery of 5-fluorouracil, mebeverine hydrochloride, indomethacin) $(92,93)$, and to image colon abnormalities using a contrast agent $(93,94)$. Jia et al. used core-shell fibers with a drugloaded core based on mucoadhesive PEO and a shell based on a $\mathrm{pH}$-sensitive copolymer derived from esters of acrylic and methacrylic acid polymer (i.e., Eudragit S100). This 
effectively delayed the release under acidic conditions, as representative of the stomach, whereas when transferred to $\mathrm{pH} 7.4$, there was sustained release up to $22 \mathrm{~h}$. They predicted that after dissolution of the shell, the fibers would adhere to the walls of the intestinal tract and provide sustained local drug release due to the mucoadhesive nature of the PEO from the core (93).

Various examples of monolithic or blended nanofibers that can or cannot delay drug release can be found in the literature $(68,95-97)$, and although some gastro-resistant coreshell nanofibers have been developed $(91,93)$, they are not a general solution for all drugs (92). Thus, delayed release does not depend only on the composition, structure, presence of drug on the nanofiber surface, or defects in the shell of the nanofibers, but also on the drug properties, including its solubility at low $\mathrm{pH}$, molecular weight, and interactions with the polymer $(18,68,92,95-97)$.

To sum up, gastro-resistant nanofibers with higher amounts of small hydrophilic drugs incorporated are more challenging to develop compared to the lower loading of nanofibers with larger hydrophobic drugs.

\section{Prolonged drug release}

Controlled drug delivery systems that release a drug over a prolonged period can improve therapeutic outcomes through reduction of drug toxicity, increased efficiency, and reduced dosing frequency, all of which will also promote patient compliance (98). An initial burst release often occurs with the use of monolithic and blended nanofibers $(51,99)$, especially if the drug crystalizes in the nanofibers or is distributed on or near the nanofiber surface $(51,76,100)$. The development of core-shell structured nanofibers can reduce this burst release, with prolonged release with minimal burst release shown (18).

Polymers that are often used for prolonged drug release are generally hydrophobic, such as PCL, poly(lactic acid) (PLA), poly(lactic-co-glycolic acid) (PLGA), zein, cellulose acetate and PMMA $(18,44,99,101)$. These polymers can only be dissolved in organic solvents, where some hydrophilic drugs are insoluble (102). In such cases, emulsion or coaxial electrospinning allow incorporation of hydrophilic drugs in the core using water-in-oil emulsions or aqueous core solutions and shell solutions prepared in organic solvents. For example, the hydrophilic drug metoclopramide hydrochloride was successfully incorporated into different core-shell fibers with PVA and the drug as the core and PCL, PLA and PLGA as shell polymers. More prolonged drug release was shown in the case of core-shell nanofibers compared to monolithic nanofibers made from the same polymer (99).

The release rate of a hydrophilic drug can be controlled by varying the physical and chemical properties of the core and shell solutions $(18,99)$. Each hydrophobic polymer used provides slightly different release kinetics (99). Drug release can be tailored by varying the flow rate ratio between the core and shell solutions. Co-axial electrospinning with the core-shell flow rate ratio of 1:5 resulted in core-shell nanofibers with fewer imperfections, which can include an incomplete shell (for e.g., see Fig. 5c), or cracks and open ends, and longer release (30 days) compared to a flow rate ratio of 1:3, which showed release over 1 day (18). Similar effects of the flow rate ratios between cores and shells have also been confirmed by other studies (54). Drug release can be additionally controlled by blending hydrophilic and hydrophobic polymers in the core (18). 
In some cases, two-phase drug release can be desired, especially when an initial burst release can relieve symptoms as soon as possible, with prolonged drug release then providing the required effects for several more hours or days. These release kinetics are especially advisable for nonsteroidal anti-inflammatory drugs, antihistamines, and anti-psychotics (103). Jiang et al. (44) reported $12 \mathrm{~h}$ biphasic release of ketoprofen encapsulated in both a fast releasing shell of polyvinylpyrrolidone and a prolonged releasing core of zein. For peripheral nerve tissue engineering, lycium barbarum polysaccharide was incorporated into core-shell nanofibers, where the core solution was an aqueous solution of this polysaccharide and the shell solution was from PLGA. Two stages of release kinetics were shown, with a fast burst release (in the first 7 days) and sustained and constant release for the following 53 days (66).

Core-shell nanofibers also enable incorporation of two or more drugs, as seen for example for core-shell nanofibers composed of a core of ibuprofen, hyaluronic acid, and PEO, and a shell of polyethylene glycol, PCL and Ag nanoparticles. All active ingredients (i.e., ibuprofen, hyaluronic acid, Ag nanoparticles) were slowly released over 20 days. The development of this multi-functional anti-adhesion nanofiber mat can reduce fibroblast attachment and penetration while simultaneously preventing post-surgical infection and inflammation (56).

\section{CORE-SHELL NANOFIBERS FOR INCORPORATION AND RELEASE OF BIOPHARMACEUTICALS}

Biopharmaceuticals are defined as protein- or nucleic-acid-based pharmaceutical substances that are used for therapeutic or in vivo diagnostic purposes and are produced by means other than direct extraction from a native (non-engineered) biological source (104). The biopharmaceutical market is rapidly increasing, and it is now the fastest growing segment of pharmaceuticals, due to their specific therapeutic effects (105). However, formulations of proteins still remain a major challenge, since they are prone to chemical and physical degradation, such as oxidation, deamidation, hydrolysis, conformational changes, undesirable adsorption to surfaces, precipitation, and aggregation (106). The problem of protein instability in aqueous solutions can be solved by freezing or drying because proteins in the solid state are more stable than the same substances in solution (107-109). Electrospinning is a promising method, which in one step enables drying of proteins and formulation of a dosage form. Several advantages of core-shell nanofibers over monolithic or blended nanofibers have been shown in terms of protein delivery (110). Coaxial electrospinning of core-shell nanofibers can reduce to a minimum the direct contact of bioactive agents in an aqueous core solution with the potentially dangerous solvents of a shell, leaving only the core-shell interface (38). Jiang et al. implied that the coaxial-electrospinning process had no detectable negative impact on either the structure or stability of lysozyme (111), whereas Ji et al. reported reduced activity of alkaline phosphatase after coaxial-electrospinning $(110,112)$. With emulsion electrospinning, small morphological changes in lysozyme were observed, which indicated some aggregation with composite fibers with higher protein loading, which was probably due to inefficient encapsulation of the protein within the fibers. In addition, the emulsification procedure resulted in a $16 \%$ reduction in protein activity, while electrospinning did not show any further increased loss of activity (32). Similarly, Frizzell et al. reported reduced protein activity after emulsion electrospin- 
ning, whereas electrospinning at a higher flow rate and inclusion of PVA increased the recovered bioactivity from 90 to $100 \%$ for horseradish peroxidase, and from 60 to $75 \%$ for alkaline phosphatase (91). It appears that protein stability during the emulsion or coaxial electrospinning processes depends on many different factors, which include the protein properties, the composition of the emulsion or core and shell solutions, and the processing parameters. In addition, it is difficult to compare various studies due to different analytical methods used, with some methods being more sensitive for the detection of protein degradation than others.

Controlled protein release is needed for several biomedical applications, such as the delivery of growth factors. Core-shell nanofibers enabled sustained release of growth factors over 30 days and decreased the burst effect of the released growth factors compared to blended nanofibers (58). Encapsulated platelet-derived growth factor-bb and lysozyme were released from core-shell nanofibers over 20 days, and they maintained high bioactivities over this period $(32,36)$. Platelet-rich plasma is a natural source of growth factors, and it has been successfully incorporated into blended chitosan/PEO nanofibers, with release over 1 day (113). More recently, platelet-rich plasma was also incorporated into core-shell nanofibers together with PVA in the core, with the shell composed of silk fibroin and PCL (11).

In some cases, a hydrophobic polymer can form an intact shell, and the active component cannot be released. To overcome this obstacle, porogens (i.e., materials that rapidly dissolve in water to open pores, such as (poly)ethylene glycol) have been added to the shell (36) or biodegradable shells have been used (32). Drug release can then be regulated by the amount and type of porogen used (36).

Protein can be released through different shell imperfections (e.g., cracks, pores, incomplete shell) (38), which more frequently occur when there is a higher volume ratio of aqueous to organic phase in the case of water-in-oil emulsion electospinning (27), and a higher ratio of core to shell solution flow rate in the case of coaxial electrospinning (18). If an incomplete core-shell structure is observed and some unencapsulated protein located close to or loosely associated with the fiber surface, the protein is likely to be released immediately (27).

Core-shell nanofibers have also been shown to be a promising option for gene delivery, especially for tissue engineering $(31,114)$. Plasmid DNA (pDNA) together with poly(ethylene glycol) was incorporated into the core of core-shell nanofibers using coaxial electrospinning. The shell consisted of the non-viral gene delivery vector poly(ethylenimine)hyaluronic acid and PCL. Complexes of pDNA with poly(ethylenimine)-hyaluronic acid were released over 60 days from core-shell nanofibers and successfully transfected cells and induced the expression of enhanced green fluorescent protein (114). Yang et al. successfully incorporated either pDNA or pDNA and poly(ethylene imine) polyplexes into the core of core-shell nanofibers using emulsion electrospinning. Poly(DL-lactide)poly(ethylene glycol) formed the shell, with poly(ethylene glycol) as the porogen to enhance the release of pDNA polyplexes, which were released over 25 days (31).

\section{CORE-SHELL NANOFIBERS FOR INCORPORATION OF PROBIOTICS}

Probiotics are live microorganisms that are beneficial for the health of the host and represent a new way of combating various infectious diseases (115). Electrospinning has been shown to be a promising single-step process to dry such bacteria and incorporate 
them into a delivery system $(116,117)$. Lopez-Rubio et al. successfully incorporated $B$. animalis Bb12 into PVA microfibers using coaxial electrospinning, without any changes in viability before or after the electrospinning process (118). The advantage of coaxial electrospinning here is that the effects of the electric charges in the core (where the bacteria are) were lowered due to the rapid escape of the charge to the outer surface of the shell at the very beginning of the core-shell jet formation (38).

\section{CONCLUSIONS}

The greatest advantage of emulsion and coaxial electrospinning is their versatility in terms of the types and sizes of the core-shell nanofibers that can be developed. They have several advantages over monolithic nanofibers, e.g., they can provide incorporation of water-soluble drugs or organic-solvent-sensitive proteins into nanofibers from hydrophobic polymers, improved drug stability, more complete drug encapsulation and greater control of the release kinetics due to a number of variable parameters. Changes in the shell and core material properties relate to variations in molecular weight, polymer type and porogen substances used, which can fine-tune the drug-release profiles and drug stability. However, fabrication of core-shell nanofibers includes several known and unknown parameters, which can be challenging in nanofiber preparation and result in low reproducibility. On several occasions, different laboratories were not able to produce similar core-shell nanofibers. Also, analytical techniques for nanofiber characterization are often time consuming and are not straightforward. In addition, in some cases, drug release from monolithic and core-shell nanofibers is very similar, and thus there is no special advantage of using the more complex processes.

Additional studies are needed in the future to better understand the effects of multiple parameters on the electrospinning process, nanofiber morphology, drug distribution in core-shell nanofibers, drug release, and in vivo effects. Use of monolithic and blended nanofibers in nanomedicine will be the first to arrive on the market, due to their easier production, higher reproducibility and already developed scale-up processes. Later, coreshell nanofibers will emerge for biomedical cases, where monolithic or blended nanofibers cannot offer such functionality with regard to drug/protein/probiotic incorporation, stability and the desired release kinetics.

Acknowledgments. - The author acknowledges financial support from the Slovenian Research Agency (Research Core Funding N P1-0189 and Project N ${ }^{\circ}$ J1- 6746 and J1-9194) and the L'Oréal and Slovenian National Commission for UNESCO for the scholarship awarded to her by the National Programme for Women in Science (2017). The author thanks Prof. Dr. Julijana Kristl for her critical review of the manuscript.

\section{REFERENCES}

1. J. Pelipenko, P. Kocbek and J. Kristl, Critical attributes of nanofibers: preparation, drug loading and tissue regeneration, Int. J. Pharm. 1-2 (2015) 57-74; https://doi.org/10.1016/j.ijpharm.2015.02.043

2. N. Bhardwaj and S. C. Kundu, Electrospinning: a fascinating fiber fabrication technique, Biotechnol. Adv. 28 (2010) 325-347; https://doi.org/10.1016/j.biotechadv.2010.01.004

3. Z. Sun, E. Zussman, A. L. Yarin, J. H. Wendorff and A. Greiner, Compound core-shell polymer nanofibers by co-electrospinning, Adv. Mater. 15 (2003) 1929-1932; https://doi.org/10.1002/ adma.200305136 
4. X. Xu, X. Zhuang, X. Chen, X. Wang, L. Yang and X. Jing, Preparation of core-sheath composite nanofibers by emulsion electrospinning, Macromol. Rapid Commun. 27 (2006) 1637-1642; https://doi. org/10.1002/marc.200600384

5. V. Beachley and X. Wen, Polymer nanofibrous structures: fabrication, biofunctionalization, and cell interactions, Prog. Polym. Sci. 35 (2010) 868-892; https://doi.org/10.1016/j.progpolymsci.2010.03.003

6. B. Janković, J. Pelipenko, M. Škarabot, I. Muševič and J. Kristl, The design trend in tissue-engineering scaffolds based on nanomechanical properties of individual electrospun nanofibers, Int. J. Pharm. 455 (2013) 338-347; https://doi.org/10.1016/j.ijpharm.2013.06.083

7. S. Sinha-Ray, S. Sinha-Ray, A. L. Yarin and B. Pourdeyhimi, Application of solution-blown 20-50$\mathrm{nm}$ nanofibers in filtration of nanoparticles: the efficient van der Waals collectors, J. Membr. Sci. 485 (2015) 132-150; https://doi.org/10.1016/j.memsci.2015.02.026

8. M. Ghaderi, M. Mousavi, H. Yousefi and M. Labbafi, All-cellulose nanocomposite film made from bagasse cellulose nanofibers for food packaging application, Carbohydr. Polym. 104 (2014) 59-65; https://doi.org/10.1016/j.carbpol.2014.01.013

9. S. Chen, H. Hou, F. Harnisch, S. A. Patil, A. A. Carmona-Martinez, S. Agarwal, Y. Zhang, S. SinhaRay, A. L. Yarin, A. Greiner and U. Schöder, Electrospun and solution blown three-dimensional carbon fiber nonwovens for application as electrodes in microbial fuel cells, Energ. Environ. Sci. 4 (2011) 1417-1421; https://doi.org/10.1039/c0ee00446d

10. H. Yoon and G. Kim, A three-dimensional polycaprolactone scaffold combined with a drug delivery system consisting of electrospun nanofibers, J. Pharm. Sci. 100 (2011) 424-430; https://doi. org/10.1002/jps.22310

11. G. Cheng, X. Ma, J. Li, Y. Cheng, Y. Cao, Z. Wang, X. Shi, Y. Du, H. Deng and Z. Li, Incorporating platelet-rich plasma into coaxial electrospun nanofibers for bone tissue engineering, Int. J. Pharm. 547 (2018) 656-666; https://doi.org/10.1016/j.ijpharm.2018.06.020

12. S. Chou, D. Carson and K. A. Woodrow, Current strategies for sustaining drug release from electrospun nanofibers, J. Control. Rel. 220, Part B (2015) 584-591; https://doi.org/10.1016/j.jconrel.2015.09.008

13. D. H. Reneker and A. L. Yarin, Electrospinning jets and polymer nanofibers, Polymer 49 (2008) 2387-2425; https://doi.org/10.1016/j.polymer.2008.02.002

14. Š. Zupančič, S. Sinha-Ray, S. Sinha-Ray, J. Kristl and A. L. Yarin, Long-term sustained ciprofloxacin release from PMMA and hydrophilic polymer blended nanofibers, Mol. Pharm. 13 (2016) 295305; https://pubs.acs.org/doi/abs/10.1021/acs.molpharmaceut.5b00804

15. A. V. Bazilevsky, A. L. Yarin and C. M. Megaridis, Co-electrospinning of core-shell fibers using a single-nozzle technique, Langmuir 23 (2007) 2311-2314; https://pubs.acs.org/doi/abs/10.1021/ la063194q

16. J. Pelipenko, J. Kristl, B. Janković, S. Baumgartner and P. Kocbek, The impact of relative humidity during electrospinning on the morphology and mechanical properties of nanofibers, Int. J. Pharm. 456 (2013) 125-134; https://doi.org/10.1016/j.ijpharm.2013.07.078

17. R. Rošic, J. Pelipenko, J. Kristl, P. Kocbek, M. Bešter-Rogač and S. Baumgartner, Physical characteristics of poly(vinyl alcohol) solutions in relation to electrospun nanofiber formation, Eur. Polym. J. 49 (2013) 290-298; http://dx.doi.org/10.1016/j.eurpolymj.2012.11.013

18. Š. Zupančič, S. Sinha-Ray, S. Sinha-Ray, J. Kristl and A. L. Yarin, Controlled release of ciprofloxacin from core-shell nanofibers with monolithic or blended core, Mol. Pharm. 13 (2016) 1393-1404; https://pubs.acs.org/doi/10.1021/acs.molpharmaceut.6b00039

19. M. Misra, J. K. Pandey and A. K. Mohanty, Biocomposites, Woodhead Publishing, 2015, pp. 201-235.

20. M. Wei, B. Kang, C. Sung and J. Mead, Core-sheath structure in electrospun nanofibers from polymer blends, Macromol. Mater. Engin. 291 (2006) 1307-1314; https://doi.org/10.1002/ mame.200600284 
21. X. H. Li, C. L. Shao and Y. C. Liu, A Simple method for controllable preparation of polymer nanotubes via single capillary electrospinning, Langmuir 23 (2007) 10920-10923; https://pubs.acs.org/ doi/abs/10.1021/la701806f

22. H. Qi, P. Hu, J. Xu and A. Wang, Encapsulation of drug reservoirs in fibers by emulsion electrospinning: morphology characterization and preliminary release assessment, Biomacromolecules 7 (2006) 2327-2330; https://pubs.acs.org/doi/abs/10.1021/bm060264z

23. A. M. Moydeen, M. S. Ali Padusha, E. F. Aboelfetoh, S. S. Al-Deyab and M. H. El-Newehy, Fabrication of electrospun poly(vinyl alcohol)/ dextran nanofibers via emulsion process as drug delivery system: kinetics and in vitro release study, Int. J. Biol. Macromol. 116 (2018) 1250-1259; https://doi. org/10.1016/j.ijbiomac.2018.05.130

24. C. Liu, C. Wang, Q. Zhao, X. Li, F. Xu, X. Yao and M. Wang, Incorporation and release of dual growth factors for nerve tissue engineering using nanofibrous bicomponent scaffolds, Biomed. Mater. 13 (2018) 044107; https://doi.org/10.1088/1748-605X/aab693

25. L. Tian, M. P. Prabhakaran, X. Ding, D. Kai and S. Ramakrishna, Emulsion electrospun vascular endothelial growth factor encapsulated poly(l-lactic acid-co- $\varepsilon$-caprolactone) nanofibers for sustained release in cardiac tissue engineering, J. Mater. Sci. 47 (2012) 3272-3281; https://doi. org/10.1007/s10853-011-6166-4

26. L. Tian, M. P. Prabhakaran, X. Ding, D. Kai and S. Ramakrishna, Emulsion electrospun nanofibers as substrates for cardiomyogenic differentiation of mesenchymal stem cells, J. Mater. Sci. Mater. Med. 24 (2013) 2577-2587; https://doi.org/10.1007/s10856-013-5003-5

27. Y. Yang, X. Li, W. Cui, S. Zhou, R. Tan and C. Wang, Structural stability and release profiles of proteins from core-shell poly (DL-lactide) ultrafine fibers prepared by emulsion electrospinning, J. Biomed. Mater. Res. A 86 (2008) 374-385; https://doi.org/10.1002/jbm.a.31595

28. X. Xu, X. Chen, P. Ma, X. Wang and X. Jing, The release behavior of doxorubicin hydrochloride from medicated fibers prepared by emulsion-electrospinning, Eur. J. Pharm. Biopharm. 70 (2008) 165-170; https://doi.org/10.1016/j.ejpb.2008.03.010

29. S. Agarwal and A. Greiner, On the way to clean and safe electrospinning-green electrospinning: emulsion and suspension electrospinning, Polym. Adv. Technol. 22 (2011) 372-378; https://doi. org/10.1002/pat.1883

30. C. Wang, L. Wang and M. Wang, Evolution of core-shell structure: from emulsions to ultrafine emulsion electrospun fibers, Mater. Lett. 124 (2014) 192-196; https://doi.org/10.1016/j.matlet.2014.03.086

31. Y. Yang, X. Li, L. Cheng, S. He, J. Zou, F. Chen and Z. Zhang, Core-sheath structured fibers with pDNA polyplex loadings for the optimal release profile and transfection efficiency as potential tissue engineering scaffolds, Acta Biomater. 7 (2011) 2533-2543; https://doi.org/10.1016/j.actbio.2011.02.031

32. Y. Yang, X. Li, M. Qi, S. Zhou and J. Weng, Release pattern and structural integrity of lysozyme encapsulated in core-sheath structured poly(DL-lactide) ultrafine fibers prepared by emulsion electrospinning, Eur. J. Pharm. Biopharm. 69 (2008) 106-116; https://doi.org/10.1016/j.ejpb.2007.10.016

33. L. Li, H. Li, Y. Qian, X. Li, G. K. Singh, L. Zhong, W. Liu, Y. Lv, K. Cai and L. Yang, Electrospun poly (๑-caprolactone)/ silk fibroin core-sheath nanofibers and their potential applications in tissue engineering and drug release, Int. J. Biol. Macromol. 49 (2011) 223-232; https://doi.org/10.1016/j. ijbiomac.2011.04.018

34. E. H. Sanders, R. Kloefkorn, G. L. Bowlin, D. G. Simpson and G. E. Wnek, Two-phase electrospinning from a single electrified jet: microencapsulation of aqueous reservoirs in poly(ethylene-covinyl acetate) fibers, Macromolecules 36 (2003) 3803-3805; https://pubs.acs.org/doi/abs/10.1021/ ma0217711

35. X. Li, Y. Su, C. He, H. Wang, H. Fong and X. Mo, Sorbitan monooleate and poly(L-lactide-co-ecaprolactone) electrospun nanofibers for endothelial cell interactions, J. Biomed. Mater. Res. A 91 (2009) 878-885; https://doi.org/10.1002/jbm.a.32286 
36. I. C. Liao, S. Y. Chew and K. W. Leong, Aligned core-shell nanofibers delivering bioactive proteins, Nanomedicine (Lond) 1 (2006) 465-471; https://doi.org/10.2217/17435889.1.4.465

37. Z. M. Huang, C. L. He, A. Yang, Y. Zhang, X. J. Han, J. Yin and Q. Wu, Encapsulating drugs in biodegradable ultrafine fibers through co-axial electrospinning, J. Biomed. Mater. Res. A 77 (2006) 169-179; https://doi.org/10.1002/jbm.a.30564

38. A. L. Yarin, Coaxial electrospinning and emulsion electrospinning of core-shell fibers, Polym. Adv. Technol. 22 (2011) 310-317; https://doi.org/10.1002/pat.1781

39. A. Arinstein, R. Avrahami and E. Zussman, Buckling behaviour of electrospun microtubes: a simple theoretical model and experimental observations, J. Phys. D: Appl. Phys. 42 (2009) 015507; https://doi.org/10.1088/0022-3727/42/1/015507

40. S. N. Reznik, A. L. Yarin, E. Zussman and L. Bercovici, Evolution of a compound droplet attached to a core-shell nozzle under the action of a strong electric field, Phys. Fluids 18 (2006) 062101; https:// doi.org/10.1063/1.2206747

41. Y. Zhang, Z. M. Huang, X. Xu, C. T. Lim and S. Ramakrishna, Preparation of core-shell structured PCL-r-gelatin bi-component nanofibers by coaxial electrospinning, Chem. Mater. 16 (2004) 34063409; https://pubs.acs.org/doi/abs/10.1021/cm049580f

42. S. Chakraborty, I. C. Liao, A. Adler and K. W. Leong, Electrohydrodynamics: a facile technique to fabricate drug delivery systems, Adv. Drug Deliv. Rev. 61 (2009) 1043-1054; https://doi.org/10.1016/j. addr.2009.07.013

43. Y. Dror, W. Salalha, R. Avrahami, E. Zussman, A. L. Yarin, R. Dersch, A. Greiner and J. H. Wendorff, One-step production of polymeric microtubes by co-electrospinning, Small 3 (2007) 10641073; https://doi.org/10.1002/smll.200600536

44. Y. N. Jiang, H. Y. Mo and D. G. Yu, Electrospun drug-loaded core-sheath PVP/zein nanofibers for biphasic drug release, Int. J. Pharm. 438 (2012) 232-239; https://doi.org/10.1016/j.ijpharm.2012.08.053

45. S. A. Theron, E. Zussman and A. L. Yarin, Experimental investigation of the governing parameters in the electrospinning of polymer solutions, Polymer 45 (2004) 2017-2030; http://dx.doi. org/10.1016/j.polymer.2004.01.024

46. J. Pelipenko, J. Kristl, R. Rošic, S. Baumgartner and P. Kocbek, Interfacial rheology: an overview of measuring techniques and its role in dispersions and electrospinning, Acta Pharm. 62 (2012) 123-140; https://doi.org/10.2478/v10007-012-0018-x

47. S. Tort, F. Acarturk and A. Besikci, Evaluation of three-layered doxycycline-collagen loaded nanofiber wound dressing, Int. J. Pharm. 529 (2017) 642-653; https://doi.org/10.1016/j.ijpharm.2017.07.027

48. R. Rošic, J. Pelipenko, P. Kocbek, S. Baumgartner, M. Bešter-Rogač and J. Kristl, The role of rheology of polymer solutions in predicting nanofiber formation by electrospinning, Eur. Polym. J. 48 (2012) 1374-1384; https://doi.org/10.1016/j.eurpolymj.2012.05.001

49. A. L. Yarin, B. Pourdeyhimi and S. Ramakrishna, Fundamentals and Applications of Micro and Nanofibers, Cambridge University Press, Cambridge 2014, pp. 25-35.

50. H. Chen, N. Wang, J. Di, Y. Zhao, Y. Song and L. Jiang, Nanowire-in-microtube structured core/ shell fibers via multifluidic coaxial electrospinning, Langmuir 26 (2010) 11291-11296; https://pubs. acs.org/doi/abs/10.1021/la100611f

51. Š. Zupančič, S. Baumgartner, Z. Lavrič, M. Petelin and J. Kristl, Local delivery of resveratrol using polycaprolactone nanofibers for treatment of periodontal disease, J. Drug Deliv. Sci. Technol. 30 (2015) 408-416; doi: http://dx.doi.org/10.1016/j.jddst.2015.07.009

52. J. Pelipenko, P. Kocbek and J. Kristl, Nanofiber diameter as a critical parameter affecting skin cell response, Eur. J. Pharm. Sci. 66 (2015) 29-35; https://doi.org/10.1016/j.ejps.2014.09.022

53. R. Li, Y. Ma, Y. Zhang, M. Zhang and D. Sun, Potential of rhBMP-2 and dexamethasone-loaded Zein/PLLA scaffolds for enhanced in vitro osteogenesis of mesenchymal stem cells, Coll. Surf. B Biointerf. 169 (2018) 384-394; https://doi.org/10.1016/j.colsurfb.2018.05.039 
54. G. Kabay, C. Demirci, G. Kaleli Can, A. E. Meydan, B. G. Dasan and M. Mutlu, A comparative study of single-needle and coaxial electrospun amyloid-like protein nanofibers to investigate hydrophilic drug release behavior, Int. J. Biol. Macromol. 114 (2018) 989-997; https://doi.org/10.1016/j. ijbiomac.2018.03.182

55. P. Bullon, H. N. Newman and M. Battino, Obesity, diabetes mellitus, atherosclerosis and chronic periodontitis: a shared pathology via oxidative stress and mitochondrial dysfunction? Periodontol. 200064 (2014) 139-153; https://doi.org/10.1111/j.1600-0757.2012.00455.x

56. K. T. Shalumon, C. Sheu, C. H. Chen, S. H. Chen, G. Jose, C. Y. Kuo and J. P. Chen, Multi-functional electrospun antibacterial core-shell nanofibrous membranes for prolonged prevention of postsurgical tendon adhesion and inflammation, Acta Biomater. 72 (2018) 121-136; https://doi. org/10.1016/j.actbio.2018.03.044

57. V. Klang, C. Valenta and N. B. Matsko, Electron microscopy of pharmaceutical systems, Micron. 44 (2013) 45-74; https://doi.org/10.1016/j.micron.2012.07.008

58. G. Jin, M. P. Prabhakaran, D. Kai and S. Ramakrishna, Controlled release of multiple epidermal induction factors through core-shell nanofibers for skin regeneration, Eur. J. Pharm. Biopharm. 85 (2013) 689-698; https://doi.org/10.1016/j.ejpb.2013.06.002

59. T. T. Nguyen, C. Ghosh, S. G. Hwang, N. Chanunpanich and J. S. Park, Porous core/sheath composite nanofibers fabricated by coaxial electrospinning as a potential mat for drug release system, Int. J. Pharm. 439 (2012) 296-306 https://doi.org/10.1016/j.ijpharm.2012.09.019

60. J. M. Deitzel, J. Kleinmeyer, D. Harris and N. C. Beck Tan, The effect of processing variables on the morphology of electrospun nanofibers and textiles, Polymer 42 (2001) 261-272; http://dx.doi. org/10.1016/S0032-3861(00)00250-0

61. X. Wang, Y. Yuan, X. Huang and T. Yue, Controlled release of protein from core-shell nanofibers prepared by emulsion electrospinning based on green chemical, J. Appl. Polym. Sci. 132 (2015) 41811: https://doi.org/10.1002/app.41811

62. Q. P. Pham, U. Sharma and A. G. Mikos, Electrospun poly(e-caprolactone) microfiber and multilayer nanofiber/ microfiber scaffolds: characterization of scaffolds and measurement of cellular infiltration, Biomacromolecules 7 (2006) 2796-2805; https://pubs.acs.org/doi/abs/10.1021/bm060680j

63. L. Ghasemi-Mobarakeh, D. Semnani and M. Morshed, A novel method for porosity measurement of various surface layers of nanofibers mat using image analysis for tissue engineering applications, J. Appl. Polym. Sci. 106 (2007) 2536-2542; https://doi.org/10.1002/app.26949

64. A. Martins, S. Chung, A. J. Pedro, R. A. Sousa, A. P. Marques, R. L. Reis and N. M. Neves, Hierarchical starch-based fibrous scaffold for bone tissue engineering applications, J. Tiss. Engineer. Regen. Med. 3 (2009) 37-42; https://doi.org/10.1002/term.132

65. S. B. Peters, D. A. Nelson, H. R. Kwon, M. Koslow, K. A. DeSantis and M. Larsen, TGF $\beta$ signaling promotes matrix assembly during mechanosensitive embryonic salivary gland restoration, $\mathrm{Ma}$ trix Biol. 43 (2015) 109-124; https://doi.org/10.1016/j.matbio.2015.01.020

66. J. Wang, L. Tian, L. He, N. Chen, S. Ramakrishna, K. F. So and X. Mo, Lycium barbarum polysaccharide encapsulated poly lactic-co-glycolic acid nanofibers: cost effective herbal medicine for potential application in peripheral nerve tissue engineering, Sci. Rep. 8 (2018) 8669; https://doi. org/10.1038/s41598-018-26837-z

67. L. Sfakis, T. Kamaldinov, A. Khmaladze, Z. F. Hosseini, D. A. Nelson, M. Larsen and J. Castracane, Mesenchymal cells affect salivary epithelial cell morphology on PGS/PLGA core/shell nanofibers, Int. J. Mol. Sci. 19 (2018) 1031; https://doi.org/10.3390/ijms19041031

68. X. Shen, D. Yu, L. Zhu, C. Branford-White, K. White and N. P. Chatterton, Electrospun diclofenac sodium loaded Eudragit(R) L 100-55 nanofibers for colon-targeted drug delivery, Int. J. Pharm. 408 (2011) 200-207; https://doi.org/10.1016/j.ijpharm.2011.01.058

69. M. Zamani, M. Morshed, J. Varshosaz and M. Jannesari, Controlled release of metronidazole benzoate from poly e-caprolactone electrospun nanofibers for periodontal diseases, Eur. J. Pharm. Biopharm. 75 (2010) 179-185; https://doi.org/10.1016/j.ejpb.2010.02.002 
70. M. C. Bottino, R. A. Arthur, R. A. Waeiss, K. Kamocki, K. S. Gregson and R. L. Gregory, Biodegradable nanofibrous drug delivery systems: effects of metronidazole and ciprofloxacin on periodontopathogens and commensal oral bacteria, Clin. Oral Investig. 18 (2014) 2151-2158; https://doi. org/10.1007/s00784-014-1201-x

71. M. Reise, R. Wyrwa, U. Muller, M. Zylinski, A. Volpel, M. Schnabelrauch, A. Berg. K. D. Jandt, D. C.Watts and B.W.Sigusch, Release of metronidazole from electrospun poly(L-lactide-co-D/L-lactide) fibers for local periodontitis treatment, Dent. Mater. 28 (2012) 179-188; https://doi.org/10.1016/j.dental.2011.12.006

72. U. Paaver, J. Heinämäki, I. Laidmäe, A. Lust, J. Kozlova, E. Sillaste, K. Kirsimäe, P. Veskia and K. Kogermann, Electrospun nanofibers as a potential controlled-release solid dispersion system for poorly water-soluble drugs, Int. J. Pharm. 479 (2015) 252-260; https://doi.org/10.1016/j. ijpharm.2014.12.024

73. S. T. Ho and D. W. Hutmacher, A comparison of micro CT with other techniques used in the characterization of scaffolds, Biomaterials 27 (2006) 1362-1376; https://doi.org/10.1016/j.biomaterials.2005.08.035

74. S. T. Yohe, Y. L. Colson and M. W. Grinstaff, Superhydrophobic materials for tunable drug release: using displacement of air to control delivery rates, J. Am. Chem. Soc. 134 (2012) 2016-2019; https://pubs.acs.org/doi/10.1021/ja211148a

75. S. T. Yohe, V. L. Herrera, Y. L. Colson and M. W. Grinstaff, Three-dimensional superhydrophobic electrospun meshes as reinforcement materials for sustained local drug delivery against colorectal cancer cells, J. Control. Rel. 162 (2012) 92-101; https://doi.org/10.1016/j.jconrel.2012.05.047

76. Š. Zupančič, L. Preem, J. Kristl, M. Putrinš, T. Tenson, P. Kocbek and K. Kogermann, Impact of PCL nanofiber mat structural properties on hydrophilic drug release and antibacterial activity on periodontal pathogens, Eur. J. Pharm. Sci. 122 (2018) 347-358; https://doi.org/10.1016/j.ejps.2018.07.024

77. W. Cui, X. Li, S. Zhou and J. Weng, Degradation patterns and surface wettability of electrospun fibrous mats, Polym. Degrad. Stab. 93 (2008) 731-738; https://doi.org/10.1016/j.polymdegradstab.2007.12.002

78. L. Ghasemi-Mobarakeh, M. P. Prabhakaran, M. Morshed, M. Nasr-Esfahani and S. Ramakrishna, Electrospun poly(e-caprolactone)/gelatin nanofibrous scaffolds for nerve tissue engineering, Biomaterials 29 (2008) 4532-4539; https://doi.org/10.1016/j.biomaterials.2008.08.007

79. S. H. Ku and C. B. Park, Human endothelial cell growth on mussel-inspired nanofiber scaffold for vascular tissue engineering, Biomaterials 31 (2010) 9431-9437; http://dx.doi.org/10.1016/j.biomaterials.2010.08.071

80. A. N. Lembach, H. Tan, I. V. Roisman, T. Gambaryan-Roisman, Y. Zhang, C. Tropea and A. L. Yarin, Drop impact, spreading, splashing, and penetration into electrospun nanofiber mats, Langmuir 26 (2010) 9516-9523; https://pubs.acs.org/doi/abs/10.1021/la100031d

81. Š. Zupančič, P. Kocbek, S. Baumgartner and J. Kristl, Contribution of nanotechnology to improved treatment of periodontal disease, Curr. Pharm. Des. 21 (2015) 3257-3271; https://doi.org/10.2174/138 1612821666150531171829

82. C. K. Brown, H. D. Friedel, A. R. Barker, L. F. Buhse, S. Keitel, T. L. Cecil, J. Kraemer, J. M. Morris, C. Reppas, M. P. Stickelmeyer, C. Yomota and V. P. Shah, FIP/AAPS joint workshop report: dissolution/in vitro release testing of novel/special dosage forms, AAPS PharmSciTech. 12 (2011) 782-794; https://doi.org/10.1208/s12249-011-9634-x

83. J. Pelipenko, P. Kocbek, B. Govedarica, R. Rošič, S. Baumgartner and J. Kristl, The topography of electrospun nanofibers and its impact on the growth and mobility of keratinocytes, Eur. J. Pharm. Biopharm. 84 (2013) 401-411; https://doi.org/10.1016/j.ejpb.2012.09.009

84. M. C. Bottino, V. Thomas, G. Schmidt, Y. K. Vohra, T. M. Chu, M. J. Kowolik and G. M. Janowski, Recent advances in the development of GTR/GBR membranes for periodontal regeneration--a materials perspective, Dent. Mater. 28 (2012) 703-721; https://doi.org/10.1016/j.dental.2012.04.022 
85. Y. Kawabata, K. Wada, M. Nakatani, S. Yamada and S. Onoue, Formulation design for poorly water-soluble drugs based on biopharmaceutics classification system: basic approaches and practical applications, Int. J. Pharm. 420 (2011) 1-10; https://doi.org/10.1016/j.ijpharm.2011.08.032

86. S. Kajdič, F. Vrečer and P. Kocbek, Preparation of poloxamer-based nanofibers for enhanced dissolution of carvedilol, Eur. J. Pharm. Sci. 117 (2018) 331-340; https://doi.org/10.1016/j.ejps.2018.03.006

87. D. G. Yu, L. M. Zhu, C. J. Branford-White, J. H. Yang, X. Wang, Y. Li and W. Qian, Solid dispersions in the form of electrospun core-sheath nanofibers, Int. J. Nanomed. 6 (2011) 3271-3280; http://dx.doi. org/10.2147/IJN.S27468

88. J. J. Li, Y. Y. Yang, D. G. Yu, Q. Du and X. L. Yang, Fast dissolving drug delivery membrane based on the ultra-thin shell of electrospun core-shell nanofibers, Eur. J. Pharm. Sci. 122 (2018) 195-204; https://doi.org/10.1016/j.ejps.2018.07.002

89. D. G. Yu, X. X. Shen, C. Branford-White, K. White, L. M. Zhu and S. W. Bligh, Oral fast-dissolving drug delivery membranes prepared from electrospun polyvinylpyrrolidone ultrafine fibers, Nanotechnology 20 (2009) 055104; https://doi.org/10.1088/0957-4484/20/5/055104

90. M. E. Aulton and K. Taylor, Aulton's Pharmaceutics: The Design and Manufacture of Medicines, 4th ed: Churchill Livingstone/Elsevier, China 2013, pp. 550-565.

91. H. Frizzell, T. J. Ohlsen and K. A. Woodrow, Protein-loaded emulsion electrospun fibers optimized for bioactivity retention and $\mathrm{pH}$-controlled release for peroral delivery of biologic therapeutics, Int. J. Pharm. 533 (2017) 99-110; https://doi.org/10.1016/j.ijpharm.2017.09.043

92. U. E. Illangakoon, D. G. Yu, B. S. Ahmad, N. P. Chatterton and G. R. Williams, 5-Fluorouracil loaded Eudragit fibers prepared by electrospinning, Int. J. Pharm. 495 (2015) 895-902; https://doi. org/10.1016/j.ijpharm.2015.09.044

93. D. Jia, Y. Gao and G. R. Williams, Core/shell poly(ethylene oxide)/ Eudragit fibers for site-specific release, Int. J. Pharm. 523 (2017) 376-385; https://doi.org/10.1016/j.ijpharm.2017.03.038

94. M. Jin, D. G. Yu, X. Wang, C. F. Geraldes, G. R. Williams and S. W. Bligh, Electrospun contrastagent-loaded fibers for colon-targeted MRI, Adv. Healthc. Mater. 5 (2016) 977-985; https://doi. org/10.1002/adhm.201500872

95. L. E. Aguilar, A. R. Unnithan, A. Amarjargal, A. P. Tiwari, S. T. Hong, C. H. Park and C. S. Kim, Electrospun polyurethane/ Eudragit (R) L100-55 composite mats for the $\mathrm{pH}$ dependent release of paclitaxel on duodenal stent cover application, Int. J. Pharm. 478 (2015) 1-8; https://doi.org/10.1016/j. ijpharm.2014.10.057

96. A. Akhgari, Z. Heshmati, H. Afrasiabi Garekani, F. Sadeghi, A. Sabbagh, B. Sharif Makhmalzadeh and A. Nokhodchi, Indomethacin electrospun nanofibers for colonic drug delivery: in vitro dissolution studies, Coll. Surf. B Biointerf. 152 (2017) 29-35; https://doi.org/10.1016/j.colsurfb.2016.12.035

97. K. Karthikeyan, S. Guhathakarta, R. Rajaram and P. S. Korrapati, Electrospun zein/eudragit nanofibers based dual drug delivery system for the simultaneous delivery of aceclofenac and pantoprazole, Int. J. Pharm. 438 (2012) 117-122; https://doi.org/10.1016/j.ijpharm.2012.07.075

98. J. Siepmann, R. A. Siegel and M. J. Rathbone, Fundamentals and Applications of Controlled Release Drug Delivery, 1 ed: Springer US 2012, pp. 19-43.

99. S. K. Tiwari, R. Tzezana, E. Zussman and S. S. Venkatraman, Optimizing partition-controlled drug release from electrospun core-shell fibers, Int. J. Pharm. 392 (2010) 209-217; https://doi. org/10.1016/j.ijpharm.2010.03.021

100. X. Sun, L. R. Nobles, H. G. Börner and R. J. Spontak, Field-driven surface segregation of biofunctional species on electrospun PMMA/PEO microfibers, Macromol. Rapid Commun. 29 (2008) 14551460; https://doi.org/10.1002/marc.200800163

101. Z. Li, H. Kang, N. Che, Z. Liu, P. Li, W. Li, C. Zhang, C. Cao, R. Liu and Y. Huang, Controlled release of liposome-encapsulated naproxen from core-sheath electrospun nanofibers, Carbohydr. Polym. 111 (2014) 18-24; https://doi.org/10.1016/j.carbpol.2014.04.017 
102. A. Szentivanyi, T. Chakradeo, H. Zernetsch and B. Glasmacher, Electrospun cellular microenvironments: understanding controlled release and scaffold structure, Adv. Drug Del. Rev. 63 (2011) 209-220; https://doi.org/10.1016/j.addr.2010.12.002

103. E. M. Fulcher, R. M. Fulcher and C. D. Soto, Pharmacology: Principles and Applications, 3rd ed., Elsevier Health Sciences, St. Louis 2012.

104. G. Walsh, Biopharmaceuticals and biotechnology medicines: an issue of nomenclature, Eur. J. Pharmaceut. Sci. 15 (2002) 135-138; http://dx.doi.org/10.1016/S0928-0987(01)00222-6

105. Y. Lokko, M. Heijde, K. Schebesta, P. Scholtèsa, M. Van Montagu and M. Giacca, Biotechnology and the bioeconomy - Towards inclusive and sustainable industrial development, New Biotechnol. 40A (2018) 5-10; https://doi.org/10.1016/j.nbt.2017.06.005

106. M. A. H. Capelle, R. Gurny and T. Arvinte, High throughput screening of protein formulation stability: Practical considerations, Eur. J. Pharmaceut. Biopharmaceut. 65 (2007) 131-148; http://dx. doi.org/10.1016/j.ejpb.2006.09.009

107. M. Manning, D. Chou, B. Murphy, R. Payne and D. Katayama, Stability of protein pharmaceuticals: an update, Pharmaceutic Res. 27 (2010) 544-575; https://doi.org/10.1007/s11095-009-0045-6

108. S. J. Shire, Formulation and manufacturability of biologics, Curr. Opin. Biotechnol. 20 (2009) 708714; https://doi.org/10.1016/j.copbio.2009.10.006

109. E. J. McNally and J. E. Hastedt, Protein Formulation and Delivery, 2nd ed., Taylor \& Francis, Boca Raton 2007, pp. 1-6.

110. H. Jiang, L. Wang and K. Zhu, Coaxial electrospinning for encapsulation and controlled release of fragile water-soluble bioactive agents, J. Control. Rel. 193 (2014) 296-303; https://doi.org/10.1016/j. jconrel.2014.04.025

111. H. Jiang, Y. Hu, Y. Li, P. Zhao, K. Zhu and W. Chen, A facile technique to prepare biodegradable coaxial electrospun nanofibers for controlled release of bioactive agents, J. Control. Rel. 108 (2005) 237-243; https://doi.org/10.1016/j.jconrel.2005.08.006

112. W. Ji, F. Yang, J. J. van den Beucken, Z. Bian, M. Fan, Z. Chen and J. A. Jansen, Fibrous scaffolds loaded with protein prepared by blend or coaxial electrospinning, Acta Biomater. 6 (2010) 41994207; https://doi.org/10.1016/j.actbio.2010.05.025

113. V. Bertoncelj, J. Pelipenko, J. Kristl, M. Jeras, M. Cukjati and P. Kocbek, Development and bioevaluation of nanofibers with blood-derived growth factors for dermal wound healing, Eur. J. Pharm. Biopharm. 88 (2014) 64-74; https://doi.org/10.1016/j.ejpb.2014.06.001

114. A. Saraf, L. S. Baggett, R. M. Raphael, F. K. Kasper and A. G. Mikos, Regulated non-viral gene delivery from coaxial electrospun fiber mesh scaffolds, J. Control. Rel. 143 (2010) 95-103; https:// doi.org/10.1016/j.jconrel.2009.12.009

115. L. V. Hooper and J. I. Gordon, Commensal host-bacterial relationships in the gut, Science 292 (2001) 1115-1118; https://doi.org/10.1016/j.jconrel.2009.12.009

116. Z. K. Nagy, I. Wagner, Á. Suhajda, T. Tobak, A. H. Harasztos, T. Vigh, P. L. Sóti, H. Pataki, K. Molnár and G. Marosi, Nanofibrous solid dosage form of living bacteria prepared by electrospinning, Express Polym. Lett. 8 (2014) 352-361; https://doi.org/10.3144/expresspolymlett.2014.39

117. Š. Zupančič, T. Rijavec, A. Lapanje, M. Petelin, J. Kristl and P. Kocbek, Nanofibers with incorporated autochthonous bacteria as potential probiotics for local treatment of periodontal disease, Biomacromolecules 19 (2018) 4299-4306; https://pubs.acs.org/doi/10.1021/acs.biomac.8b01181

118. A. Lopez-Rubio, E. Sanchez, Y. Sanz and J. M. Lagaron, Encapsulation of living bifidobacteria in ultrathin PVOH electrospun fibers, Biomacromolecules 10 (2009) 2823-2829; https://pubs.acs.org/ doi/abs/10.1021/bm900660b 